\title{
Response Patterns of Olfactory Bulb Neurons to Stimulation of Distilled Water and Odorous Solutions
}

\author{
Heihachiro ARIto and Sadayuki F. TAKAGI* \\ National Institute of Industrial Health, Kawasaki, 213 Japan \\ * Department of Physiology, School of Medicine, Gunma University, \\ Maebashi, 371 Japan
}

\begin{abstract}
Summary Responses of 50 olfactory bulb neurons of the bullfrog to odorous solutions of ethyl $n$-butyrate were composed mainly of facilitation, inhibition and no response, whereas those of the same neurons to water were mainly of facilitation and delayed facilitation. The responses to water tended to continue longer than those to the odorous solutions.
\end{abstract}

In a preceding paper (ARITO et al., 1978), the water response of the frog olfactory epithelium was studied by recording discharges of the olfactory bulb neurons, and its underlying mechanism was discussed with reference to the water response of the gustatory organs. The present study was undertaken to clarify probable differences between the responses to distilled water and those to odorous solutions in the olfactory bulb neurons.

Bullfrogs (Rana catesbiana) were used. The surgical procedure and technique for recording the spike potentials of olfactory bulb neurons were the same as previously described (ARITO et al., 1978). Three stimulants were applied: distilled water prepared by distillation of deionized water $(100 \mu 1)$; and $1.5 \mathrm{~mm}$ ethyl $n$-butyrate (ENB) and $15 \mathrm{~mm}$ ENB, both of the reagent grade, dissolved in isotonic $\mathrm{NaCl}$ solutions $(50 \mu \mathrm{l}$ each). When recording of stable neuronal activity was successful in the olfactory bulb, the three stimulants were dripped one after another on the olfactory epithelium of the recording side. One minute before the application of a stimulant, $100 \mu \mathrm{l}$ of an isotonic (116 mM) $\mathrm{NaCl}$ solution was applied as an adapting solution (ARITO et al., 1978). This adapting solution was also effective in removing any possible remaining stimulant applied previously. It has been shown already that dripping itself does not elicit any response at all (TAKAGI et al., 1978). These experimental procedures were carried out every 2 or $3 \mathrm{~min}$ : and the response types of 50 olfactory bulb neurons were examined. The numbers of the spontaneously

Received for publication May 11, 1979

有藤平八郎，高木貞敬 

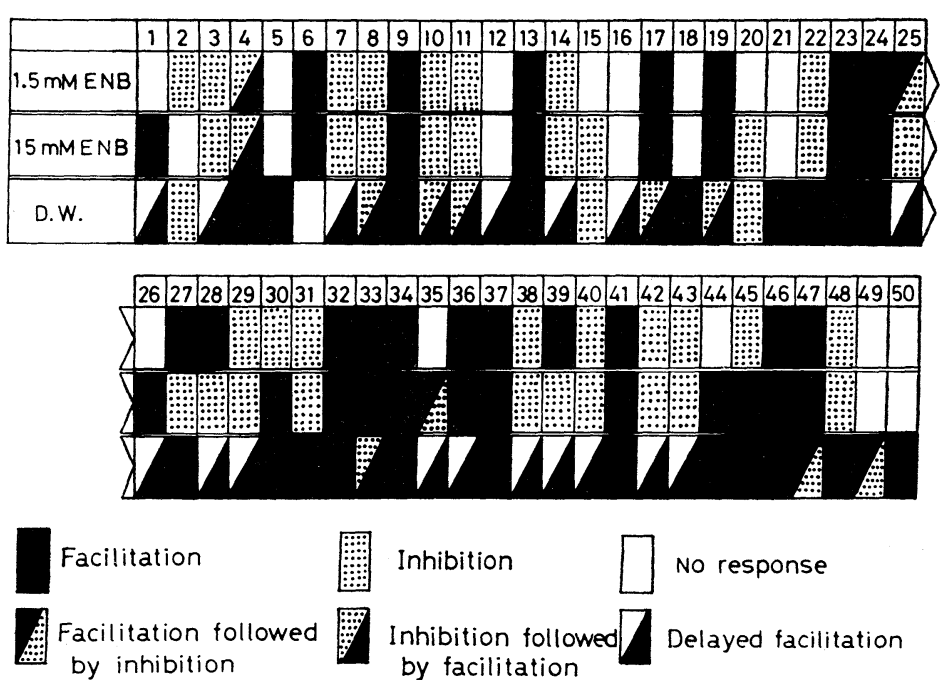

No response by facilitation

Fig. 1. Response types of 50 olfactory bulb neurons elicited by $1.5 \mathrm{~mm}$ and $15 \mathrm{~mm}$ ENB solutions and distilled water (D.W.). The response types are indicated by six differentially-shaded blocks below the matrix. The horizontal column indicates the number of the olfactory bulb neurons examined.

occurring spikes were counted every $5 \mathrm{sec}$ bin for $20 \mathrm{sec}$ before stimulation, and they then were averaged. Next, this mean number was compared with the spike numbers counted during the poststimulation period of every $5 \mathrm{sec}$. By these countings the responses were classified into the following six categories: (1) facilitatory response (an increase in the number of spikes), (2) inhibitory response (a decrease in the number of spikes), (3) no response (no significant change in the number of spikes), (4) facilitation followed by inhibition, (5) inhibition followed by facilitation, and (6) delayed facilitation (an increase in the number of spikes which occurred later than $5 \mathrm{sec}$ after the onset of stimulation).

All the responses are summarized in Fig. 1. When $1.5 \mathrm{~mm}$ ENB solution was applied, the response types of the 50 neurons were composed of facilitation in $36 \%$, inhibition in $34 \%$, no response in $26 \%$, facilitation followed by inhibition in $2 \%$ and inhibition followed by facilitation in $2 \%$. When $15 \mathrm{mM} \mathrm{ENB}$ solution was applied, however, the response types of the same neurons were composed of facilitation in $40 \%$, inhibition in $40 \%$, no response in $16 \%$, facilitation followed by inhibition in $2 \%$ and inhibition followed by facilitation in $2 \%$. When distilled water was applied, the response types of the same neurons were composed of facilitation in $42 \%$, delayed facilitation in $34 \%$, inhibition followed by facilitation in $12 \%$, inhibition in $6 \%$, facilitation followd by inhibition in $4 \%$ and no response in $2 \%$. Some characteristic differences were found between the water and odorous responses: Firstly, the delayed facilitatory response was observed only in the water response. Secondly, the inhibitory 

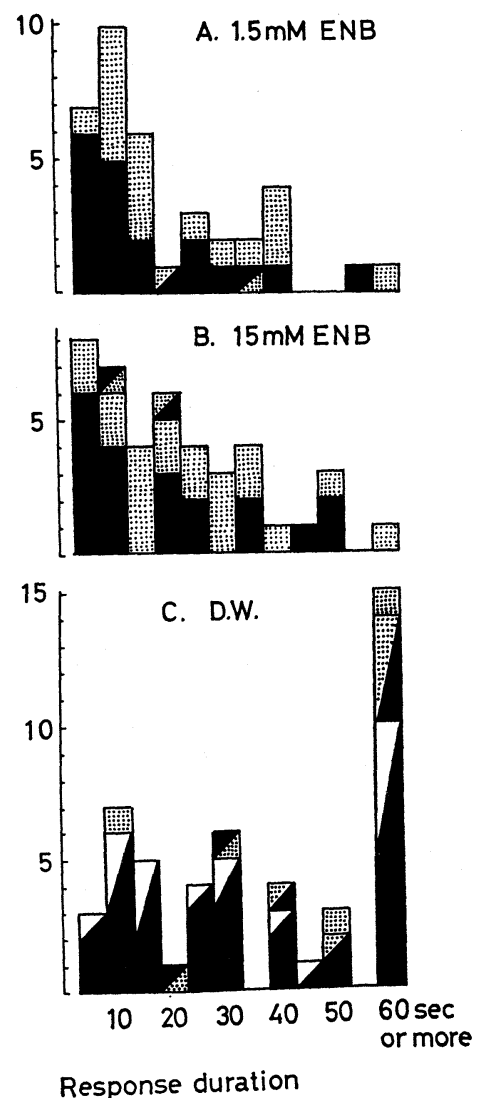

Fig. 2. Histograms for response durations of 50 olfactory bulb neurons to $1.5 \mathrm{~mm}$ ENB (A) and $15 \mathrm{~mm}$ ENB solutions (B) and distilled water (C). The response types are shown by the same six kinds of blocks as in Fig. 1. The ordinate of each histogram indicates the number of olfactory bulb neurons.

or no response type was observed more frequently in odorous stimulation than in water stimulation. Our results concerning the occurrence rates of each response type to the odorous solutions were not significantly different from the results obtained by other investigators who applied odorous gases of different kinds (Döving, 1966; Higashino et al., 1969; Mathews, 1972; KAUER, 1974). Therefore, as IINo and TAKAGI (1978) suggested, there may be no essential difference between the responses to odors in a gaseous phase and in an aqueous phase.

In the present experiment, stimulation with water caused the facilitatory and delayed facilitatory responses in $76 \%$ of the 50 neurons and no response in $2 \%$, whereas in the previous experiment (ARITO et al., 1978) $53 \%$ of the 45 olfactory bulb neurons showed facilitation, including delayed facilitation, 
and no response in $33 \%$. This discrepancy between the two studies can be explained from our hypothesis on the generation of the water response (ARITO et al., 1978): The volume of distilled water applied was $50 \mu 1$ in the previous study and $100 \mu \mathrm{l}$ in the present study. This increased volume of water is considered to be more effective in removing the adsorbed cations from the surface of the olfactory epithelium and thus results in an increase of the number of olfactory bulb neurons responding in the facilitatory way and a decrease of the number of neurons showing no response.

Durations of the responses of olfactory bulb neurons to distilled water, $1.5 \mathrm{~mm}$ and $15 \mathrm{~mm}$ ENB solutions were examined in the same 50 neurons. The histograms A, B and $\mathrm{C}$ shown in Fig. 2 indicate relations between the response durations and the response types. The neurons which showed a facilitatory response of less than $5 \mathrm{sec}$ to the ENB solutions were most numerous, and the neurons which showed longer facilitatory responses generally decreased with increasing durations. The inhibitory responses elicited by the ENB solutions showed a tendency to continue longer than the facilitatory ones. In contrast, distilled water elicited responses with durations longer than $60 \mathrm{sec}$ most frequently. With respect to the sustained nature, the water response in the olfactory epithelium is similar to the one in the frog tongue (KOKETSU, 1951; AKaike and SATO, 1976). The water response was depressed immediately by the application of an isotonic $\mathrm{NaCl}$ solution on the olfactory epithelium (ARITo et al., 1978), while it was reported that rich sodium ions are secreted from Bowman's glands (Ref. (7) of Moulton, 1976). Consequently, it is considered that the water response continues until sodium ions secreted from Bowman's glands increase to a certain concentration on the surface of the olfactory epithelium. Thus, it may be said that the sustained nature of the water response of the olfactory bulb neurons reflects a long-lasting activity of the olfactory cell. However, KAUER and SHEPHERD (1977) correlated temporal patterns of the responses to odors of the salamander olfactory bulb neurons with some basic properties of synaptic circuits in the bulb. Consequently, there remains a possibility that the long duration of the water response and the short duration of the odorous response may be due to the activity of the synaptic circuits in the bulb. In order to clarify this problem, it is necessary to record the responses to distilled water and to odorous solutions directly from the olfactory cell.

\section{REFERENCES}

Akaike, N. and Sato, M. (1976) Water response in frog taste cells. Comp. Biochem. Physiol. [A], 54: 149-156.

ARIto, H., IINo, M., and TAKAGI, S. F. (1978) Water response of the frog olfactory epithelium as observed from the olfactory bulb. J. Physiol. (Lond.), 279: 605-619.

Doving, K. B. (1966) An electrophysiological study of odour similarities of homologous 
substances. J. Physiol. (Lond.), 186: 97-109.

Higashino, S., Takeuchi, H., and Amoore, J. E. (1969) Mechanism of olfactory discrimination in the olfactory bulb of the bullfrog. In: Olfaction and Taste III, ed. by Pfaffman, C. The Rockefeller Univ. Press, New York, pp. 192-211.

IINO, M. and TAKAGI, S. F. (1978) Stimulation of the olfactory epithelium with odorants in gaseous and aqueous phases. Jpn. J. Physiol., 28: 149-157.

KAUER, J. S. (1974) Response patterns of amphibian olfactory bulb neurons to odour stimulation. J. Physiol. (Lond.), 243: 695-715.

KAUER, J. S. and Shepherd, G. M. (1977) Analysis of the onset phase of olfactory bulb unit responses to odour pulses in the salamander. J. Physiol. (Lond.), 272: 495-516.

Koketsu, K. (1951) Impulses from receptors in the tongue of a frog. Kyushu Mem. Med. Sci., 2: 53-61.

Mathews, D. F. (1972) Response patterns of single neurons in tortoise olfactory epithelium and olfactory bulb. J. Gen. Physiol., 60: 166-180.

Moulton, D. G. (1976) Spatial patterning of response of odour in the peripheral olfactory system. Physiol. Rev., 56: 578-593.

TAKAGI, S. F., IINO, M., and YARITA, H. (1978) Effects of gustatory stimulants upon the olfactory epithelium of the bullfrog and the carp. Jpn. J. Physiol., 28: 109-128. 